\title{
A PRÁTICA COMO COMPONENTE CURRICULAR E SUA IMPLEMENTAÇÃO EM UM CURSO DE FORMAÇÃO SUPERIOR DE TRADUTORES E INTÉRPRETES DE LÍNGUA DE SINAIS
}

\author{
PRACTICE AS A CURRICULAR COMPONENT AND ITS IMPLEMENTATION IN A \\ HIGHER EDUCATION COURSE OF TRANSLATORS AND INTERPRETERS OF \\ SIGN LANGUAGE
}

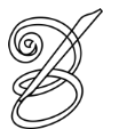 \\ Neiva de Aquino ALBRES \\ Universidade Federal de Santa Catarina \\ José Ednilson Gomes de SOUZA JUNIOR ${ }^{\mathrm{ii}}$ \\ Universidade Federal de Santa Catarina
}

\begin{abstract}
Resumo: O presente trabalho tem por objetivo descrever e analisar a distribuição e configuração das atividades de Prática como Componente Curricular - PCC em um curso de Bacharelado em Letras Libras (para formação de tradutores e intérpretes de Libras/Português). É uma pesquisa de cunho qualitativo e tem como instrumento de coleta de dados a análise documental (projeto político pedagógico e planos de ensino), visando a analisar como as práticas entendidas como componentes curriculares estão distribuídas no programa do curso a partir das Resoluções CNE/CP 1/2002 e CNE/CP 2/2002 e quais atividades são propostas pelos referidos professores para este fim. O aporte teórico baseia-se em contribuições dos Estudos da Tradução nas perspectivas histórico-cultural e enunciativo-discursiva da linguagem. Os resultados apontam que os professores propõem diferentes atividades, articulando as dimensões teórica e prática da profissão, o que favorece ao aluno a reflexão concernente à realidade da carreira. Apesar de a PCC haver sido idealizado inicialmente para cursos de licenciatura, apreciamos sua aplicação neste curso de bacharelado.
\end{abstract}

Palavras-chave: Currículo. Formação de intérpretes. Ensino de tradução.

Abstract: The aim of this work is to describe and analyze the distribution and configuration of the Practice as a Curricular Component - PCC in a bachelor's course in Brazilian Sign Language (for the training of translators and interpreters of Brazilian Sign Language/Portuguese). It is a research of qualitative nature that uses document analysis as a means of data collection (course outline and teaching plans), aiming to analyze how practical lessons, understood as curricular components, are distributed in the layout of the course, following Resolutions CNE/CP 1/2002 and CNE/CP 2/2002, and what activities are proposed by the professors to this purpose. The theoretical approach is based on contributions from Translation Studies in the historical-cultural and enunciativediscursive perspectives of language. The research shows that the professors propose different activities articulating the theoretical and practical dimensions of the profession, which encourages the students to reflect on the reality of the career. Although PCC has been initially idealized for licentiate courses, its application in this bachelor's course will be appreciated.

Keywords: Curriculum. Interpreters training. Translation teaching.

RECEBIDO EM: 20 de março de 2018

ACEITO EM: 15 de dezembro de 2018

PUBLICADO EM: janeiro 2019

ALBRES, SOUZA JUNIOR. A prática como componente curricular e sua implementação em um curso de formação superior de tradutores e intérpretes de língua de sinais

Belas Infiéis, v. 8, n. 1, p. 163-188, 2019. DOI: 10.26512/belasinfieis.v8.n1.2019.22632 


\section{Introdução}

Historicamente, os intérpretes de língua de sinais aprendiam o ofício na prática, inseridos na comunidade surda ou em cursos livres, sem uma discussão curricular e pedagógica (SANTOS, 2006; LACERDA, 2010; SILVA, 2012). No entanto, se anteriormente, em geral, não se tinha espaço para formação, atualmente expande-se a formação profissional de intérprete em cursos de graduação específicos, principalmente em decorrência do Decreto Federal 5.626/05 (FERREIRA, 2015; MARTINS \& NASCIMENTO, 2015; FARIA \& GALANMANAS, 2018).

O reconhecimento da profissão de Tradutor e Intérprete de Libras-Língua Portuguesa (TILS) (BRASIL, 2010), a política de acessibilidade (BRASIL, 2000), a de educação inclusiva (BRASIL, 2008) e a Lei Brasileira de Inclusão (Brasil, 2016) requerem da formação um conhecimento teórico-prático para que o profissional possa atuar em diferentes contextos sociais. O curso Letras Libras foi criado em 2006, primeiramente com a habilitação em licenciatura e, em 2008, com o curso de bacharelado, contemplando a formação de tradutores e intérpretes de língua de sinais pela Universidade Federal de Santa Catarina (QUADROS, 2015).

164 O Plano Nacional dos Direitos da Pessoa com Deficiência - Viver sem Limite foi lançado em 2011 e previu a criação de 25 cursos para contemplar a formação de professores e tradutores e intérpretes de Libras em todas as regiões do país. Todavia, até o momento, apenas oito instituições públicas implantaram a formação em nível de graduação para TILS: UFSC, UFG, UFGD, UFRR, UFSCar, UFRJ, UFES e UFRGS.

Constatamos uma aproximação do curso em análise, nesta pesquisa, aos documentos legais (Resoluções CNE/CP 1/2002 e CNE/CP 2/2002¹) com o objetivo de regulamentar a formação de professores no Brasil. A Lei de Diretrizes e Bases da Educação Nacional - LDBN, instituída em 1996, dedica um capítulo, "Dos Profissionais da Educação", à necessidade de “associação entre teorias e práticas” e estabelece no mínimo 300 horas para atividades de prática de ensino (MONTEIRO, 2013).

A Resolução CNE/CP 2, de 19 de fevereiro de 2002, regeu o assunto e determinou que o Projeto Político Pedagógico (PPP) de cursos de licenciatura deveriam garantir 400 horas de Prática como Componente Curricular (PCC), vivenciadas ao longo do curso, diferenciando-a do estágio curricular supervisionado, que corresponde a outras 400 horas, a partir da segunda metade do curso. Contudo, os cursos de bacharelado são regidos pela Lei $\mathrm{N}^{\circ} 11.788$, de 25 de setembro de 2008, que não segue esse mesmo princípio. 
A Prática como Componente Curricular na Resolução CNE/CP 1, de 18 de fevereiro de 2002, se traduz em:

\begin{abstract}
Art. 13. Em tempo e espaço curricular específico, a coordenação da dimensão prática transcenderá o estágio e terá como finalidade promover a articulação das diferentes práticas, numa perspectiva interdisciplinar.

$\S 1^{\circ}$ A prática será desenvolvida com ênfase nos procedimentos de observação e reflexão, visando à atuação em situações contextualizadas, com o registro dessas observações realizadas e a resolução de situações-problema. § $2^{\circ} \mathrm{A}$ presença da prática profissional na formação do professor, que não prescinde da observação e ação direta, poderá ser enriquecida com tecnologias da informação, incluídos o computador e o vídeo, narrativas orais e escritas de professores, produções de alunos, situações simuladoras e estudo de casos. (BRASIL, Resolução 1, 2002, Art. 13, $\S 1^{\circ}$ e $2^{\circ}$ ).
\end{abstract}

Pesquisadores do campo do currículo têm indicado ser interessante a orientação de articulação entre teoria e prática (LIBÂNEO, 2000; MOREIRA, 2002). Entretanto, há uma preocupação para que a "PCC integrada ao projeto político-pedagógico do curso [...] colabore com o aprimoramento da formação do professor, de modo a superar ajustes curriculares formais nos quais a PCC serve apenas como mecanismo facilitador do cumprimento da carga horária mínima do curso" (SOUZA-NETO, SILVA, 2014, p. 889).

Para Moraes (s/d, p. 07), "não deve ocorrer a criação de disciplinas de caráter unicamente prático. A dimensão prática parece que deve vir diluída ao longo do curso entre as disciplinas de caráter propositivo, estabelecendo uma relação dialética entre teoria e prática". Essa articulação se faz importante e envolve várias instâncias do projeto pedagógico e variados aspectos para a construção da PCC. "Os sentidos da PCC nos documentos do CNE são produzidos a partir de discursos 'emprestados' ou intertextuais, como: articulação teoria e prática, aproximação universidade e escola, o conceito de competência, entre outros." (BARBOSA; CASSIANI, 2014, p. 201, aspas dos autores). Todavia, difíceis de serem viabilizados no cotidiano da universidade, discursos são registrados em textos (documentos dos cursos), mas executados de formas distintas.

A partir da leitura dos autores acima citados, bem como dos instrumentos normativos mencionados, é possível vislumbrar a PCC na formação de tradutores e intérpretes, considerando que a compreensão do princípio da indissociabilidade teoria-prática na formação profissional também se faz interessante para Tradutores e Intérpretes de Línguas de Sinais TILS, não sendo profícua a espera até o meio ou o final do curso para vivenciar espaços educativos que reflitam a prática profissional, para desenvolver atividades de estágio curricular supervisionado.

ALBRES, SOUZA JUNIOR. A prática como componente curricular e sua implementação em um curso de formação superior de tradutores e intérpretes de língua de sinais

Belas Infiéis, v. 8, n. 1, p. 163-188, 2019. DOI: 10.26512/belasinfieis.v8.n1.2019.22632 
Interessa-nos compreender como implementar a PCC em curso de formação superior de TILS. Em que disciplinas são alocadas, como se estabelece na prática pedagógica, em que atividades e quais suas implicações para formação teórico-prática do futuro profissional.

\section{Teoria e prática na formação de tradutores e intérpretes}

Nesta seção, expomos o aporte teórico que norteou a pesquisa. Apresentamos contribuições dos Estudos da Tradução, inicialmente. Considerando que a compreensão de qualquer fenômeno a ser estudado merece seu delineamento histórico e cultural, apontamos marcos da formação dos tradutores e intérpretes no Brasil, finalizando a seção com apontamentos a partir da perspectiva enunciativo-discursiva da linguagem sobre o ensino de língua.

Historicamente, a atuação de tradutores e intérpretes de diferentes pares linguísticos precedem qualquer estudo ou formação específica. Com a exigência de melhor qualificação e com o desenvolvimento da ciência neste campo, vislumbramos mudanças.

A formação superior em tradução no Brasil iniciou-se em 1969 com a criação do curso

166 de Letras com habilitação em revisor-tradutor-intérprete na Pontifícia Universidade Católica do Rio de Janeiro. Na década seguinte, outros quatro cursos pioneiros de bacharelados em Letras com habilitação em tradutor e intérprete são criados: em 1973, o do Centro Universitário IberoAmericano (UNIBERO) e o da Universidade Federal do Rio Grande do Sul (UFRGS), em 1978, o da Universidade de São Paulo (UNESP), e em 1980, o da Universidade de Brasília (UnB).

O estudo sobre formação profissional no Brasil é marcado pela publicação pioneira de Delto de Mattos, em 1980, intitulada “A Formação do Tradutor em Nível Universitário”. Desde então, vem-se apresentando e discutindo a dicotomia entre teoria e prática.

A pesquisa sobre o ensino de tradução é apontada por Williams \& Chesterman (2002) como uma das áreas de interesse dos Estudos da Tradução. Não obstante, a formação de TILS é problematizada atualmente, considerando diferentes aspectos pedagógicos (NAPIER, 2009; MARSCHARK, PETERSON e WINSTON, 2005; ROY, 2005; 2002). Analisando a diversidade dos contextos internacionais, uma tentativa de planificar o conteúdo básico, teórico e prático para a formação de TILS no mundo foi publicada em 2007 pela World Association of Sign Language Interpreters, sob o título de WASLI Interpreter Education Guidelines, que discorre sobre currículo e ensino, indicando a necessidade de articular teoria e prática em atividades diretas com a comunidade (WASLI, 2017). 
Pesquisadores e formadores de TILS, no Brasil, também têm se dedicado a temas relacionados ao currículo, à didática e ao ensino para a formação de TILS. Selecionamos alguns trabalhos produzidos pelos próprios formadores, pois consideramos que a prática de ensino provoca reflexões específicas, contribuindo para o campo da didática e do ensino. A atividade docente

[...] coloca os alunos participantes e os professores pesquisadores como coautores do processo de produção, proporcionando-lhes oportunidade de tematização da prática docente à luz das teorias que lhes dão sustentação, para contribuírem com a discussão sobre formação de tradutores (ALBRES; NASCIMENTO, 2014, p. 224).

Os alunos vivenciam o currículo e os professores o reconfiguram com suas práticas. Os professores interpretam o currículo, algo abstrato e idealizado, e o colocam em ação em sala de aula. Concordamos com a afirmação de Apple (2002) de que o currículo é a seleção da cultura para a formação em uma determinada área:

\footnotetext{
O currículo nunca é apenas um conjunto neutro de conhecimentos, que de algum modo aparece nos textos e nas salas de aula de uma nação. Ele é sempre parte de uma tradição seletiva, resultado da seleção de alguém, da visão de algum grupo acerca do que seja conhecimento legítimo. É produto das tensões, conflitos e concessões culturais, políticas e econômicas que organizam e desorganizam o povo (APPLE, 2002, p.59).
}

Estudos sobre currículo apontam diferentes escolhas, diferentes concepções sobre a profissão e a academia. Albres $(2010,2011)$ estudou a estrutura organizacional de currículos de três cursos de pós-graduação para a formação de TILS e constatou que, em sua maioria, "apresentam pequena carga horária de prática de interpretação e sem distinguir a direção da tradução, ou seja, qual a língua alvo e fonte treinada" (ALBRES, 2010, p.01). A carga horária destinada a diferentes disciplinas teóricas é maior do que a destinada àquelas com algum caráter prático, além de essas não serem articuladas.

Sousa e Lemos (2010, p. 01) analisaram a avaliação da competência tradutória e interpretativa ao final de curso livre de formação de TILS com 300h, "abrangendo disciplinas sobre o histórico da comunidade surda, cultura e identidade surda, técnicas de interpretação LIBRAS/Português/LIBRAS, estrutura linguística da LIBRAS, ética [...]”. Conforme as autoras, de 300 horas, 130 são dedicadas a laboratórios de interpretação, o que propiciou competências para a atuação profissional. 
Nascimento et al. (2012) analisaram um currículo de curso de Extensão para Tradutores Intérpretes de Libras Português: Intérprete Educacional. O curso é de 130 horas, sendo 66 de prática interpretativa e 64 de conteúdo teórico, contemplados em três eixos: pedagógico/educacional, sócio/antropológico e linguístico/interpretativo. Há um equilíbrio de horas entre teoria e prática, sendo intercaladas no decorrer da execução das disciplinas. Os autores consideram ser importante olhar também as práticas pedagógicas aplicadas nas disciplinas desenhadas em um currículo.

Para Lacerda (2010, pp.137-138), “o intérprete molda-se às demandas da prática e vai constituindo-se como TILS nas e pelas experiências que vai vivenciando". Desta forma, um curso de formação precisa refletir as necessidades de atuação do profissional, trazendo para a sala de aula atividades práticas refletidas pelas teorias da tradução. "A vivência prática de modos de versar de uma língua para outra deve ser acrescentada à formação teórica sobre as línguas, sobre aspectos linguísticos e culturais, entre outros” (LACERDA, 2010, p.146). A autora pondera ainda que o trabalho de interpretação não se reduz a um trabalho linguístico. De tal modo, aspectos culturais e sociais precisam ser considerados quando se pretende 168 compreender um enunciado e essa perspectiva precisa fazer parte da formação.

Outros formadores/pesquisadores têm se preocupado com as questões da prática de ensino (MOREIRA, 2000; ALBRES, NASCIMENTO, 2014). A partir de então, apresentaremos algumas experiências didático-pedagógicas.

Albres e Nascimento, (2014) apresentam a aplicação de sequência didática de tradução de um livro de literatura infanto-juvenil. Os autores destacam que a concepção de língua e de ensino dos professores regem suas práticas, e indicam que os professores são conduzidos por uma concepção teórico-prática indissociável, embasados em uma perspectiva dialógicopolifônica e histórico-cultural (ALBRES, NASCIMENTO 2014).

Ainda sobre concepção de ensino, Almeida e Lodi (2012, p. 112) compreendem a tradução e a interpretação "como lugar de construção e produção de sentidos, logo um trabalho de e com a linguagem". Afirmam embasar-se em Bakhtin (2000), esclarecendo que, nesta perspectiva, a língua materializa-se nas enunciações e, portanto, não lidamos nunca com palavras isoladas e com suas significações, mas com o enunciado concreto e com o sentido deste enunciado, logo do discurso (ALMEIDA; LODI, 2012). 
Almeida (2010) reflete sobre atividades didático-pedagógicas utilizadas para embasar os alunos nas diferentes estratégias de atuação, possibilitadas por vivências simuladas e reais de práticas profissionais:

Nesta relação formativa cabe aos professores envolvidos levar os alunos (futuros intérpretes) a refletirem teoricamente sobre sua prática da mesma forma que, quando em atividades práticas, levá-los a reconhecer a teoria que subjaz o processo interpretativo (ALMEIDA, 2010, p.47).

A autora trata da teoria como um conhecimento que subjaz à prática, que embasa a atuação, mas que por si só não se sustenta quando utilizado de maneira exclusiva no processo de formação:

\footnotetext{
Nesta relação entre teoria e prática, defendemos o desenvolvimento de práticas que possibilitem aos alunos a vivência nas línguas, em situações simuladas e/ou reais de interpretação, para que a partir delas, muitos dos aspectos descritos anteriormente possam ser abordados e, gradualmente, apropriados pelos alunos. Desta forma, eles participam ativamente de seu próprio processo de formação, de construção conjunta de sentidos entre discursos em duas línguas, dando-lhes segurança para assumir o mercado profissional futuramente (ALMEIDA, 2010, p.47).
}

Esta discussão se integra diretamente àquelas sobre profissionalização de carreiras de forma geral que, por sua vez, demarcam parte do movimento de reformas educacionais em andamento em todo o mundo, registrado no Brasil na Lei de Diretrizes e Bases da Educação Nacional - LDBN (BRASIL, 1996), que, mais tarde, fundamentaria a instituição de parâmetros e diretrizes para a formação.

Percebemos que esta discussão se fez proeminente no campo de formação de professores e ainda é incipiente na formação de outros profissionais, como tradutores e intérpretes. No campo das licenciaturas, configura "[...] uma verdadeira e profunda mutação do modelo de formação até então em vigor nas universidades: mais que os conteúdos, disciplinas e pesquisa universitária, doravante são os saberes da ação [...], e as práticas profissionais que constituem o quadro de referência da nova formação [...]” (BORGES; TARDIF, 2001, p.16).

Embora os bacharelados não tenham essa relação sistemática formativa entre teoria $\mathrm{e}$ prática, o curso analisado fez esse movimento, visto que seu projeto foi desenvolvido com base no curso de Letras Libras licenciatura que o precedeu na instituição analisada.

Teoria e prática podem ser empregadas em diferentes contextos, como na pesquisa, formação, política, entre outros. Na perspectiva enunciativo-discursiva, uma concepção de linguagem que congregue teoria e prática denomina-a práxis. No campo da pesquisa 
materialista histórico dialética, existe a concepção de que o homem não só interpreta o mundo, mas o transforma. Então, age sobre o mundo e constitui-se pela cultura e linguagem que vivencia.

Aproximando-nos da filosofia da linguagem:

\begin{abstract}
A língua é dinâmica; renova-se de forma contínua, num processo histórico evolutivo ininterrupto que se realiza por meio de situações em que ocorrem comunicações verbais concretas, nos processos interativos que se dão entre os falantes da língua. Esses processos interativos estão organizados pelas enunciações dos falantes dentro de uma situação interativa dada (MILLER, 2009, p. 575-476).
\end{abstract}

Língua em uso, em processos interativos, mapeados como aplicados em contextos de ensino de línguas ou de tradução e interpretação de línguas requerem sujeitos preparados para o inusitado, para interpretar no sentido da busca pela compreensão do dito em contextos específicos de enunciação e abertos ao caráter de novidade da língua em uso. Desta forma, é necessário que a formação de tradutores e intérpretes

[...] forneça ao aluno compreensão da língua não como um sistema fechado de regras e normas que devem ser memorizados para posterior uso, mas como uma realidade viva cuja substância é constituída por interações verbais concretizadas por meio do jogo das enunciações verbais que se estabelece entre os usuários da língua (MILLER, 2009, p.480).

Nessa perspectiva, a linguagem é mais do que apenas um sistema linguístico. Aliás, como reflete o autor, a palavra é um signo social e não deve ser encarada como algo estanque, neutro, dissociado das práticas discursivas da linguagem, uma vez que esta visão é uma abstração de algo concreto. Para o ensino de seu uso em processos de tradução e interpretação, a linguagem deve ser vivida, experienciada em seu processo de versão de uma língua em outra, de sua articulação com outras linguagens, o que prova que se não se aprende apenas pela teoria e, sim, pela experiência, pois na prática social de uso da linguagem se aprende a interpretar interpretando.

Dessa forma, o currículo, a didática e o ensino devem conduzir o aprendiz de TILS a se preparar para enfrentar o jogo das enunciações tanto de português para Libras quanto de Libras para português. De tal modo, a prática e a teoria são indissociáveis. A partir da prática, se compreende o que já se construiu como teoria para o campo, e a teoria só se sustenta embasada em uma prática de tradução ou de interpretação. 
As atividades pedagógicas organizadas em sala de aula (ambiente formal de ensino de língua e de sua tradução ou interpretação) devem prever o desenvolvimento de diferentes habilidades. Como afirmam Bakhtin/Volochínov (1992),

[...] o essencial na tarefa de descodificação não consiste em reconhecer a forma utilizada, mas compreendê-la num contexto concreto preciso, compreender sua significação numa enunciação particular. Em suma, trata-se de perceber seu caráter de novidade e não somente sua conformidade à norma (BAKHTIN/VOLOCHÍNOV, 1992 [1929], p. 93).

Ao realizar seus estudos filosóficos da linguagem, Bakhtin (2010, p. 283) observa que "[...] aprender a falar significa aprender a construir enunciados, porque falamos por enunciados e não por orações isoladas, e evidentemente, não por palavras isoladas", nem por exercícios divorciados das práticas de usos efetivos da linguagem, sem que exista um objetivo claro e definido que possa justificá-los. Assim, a formação de tradutores e intérpretes deve prever práticas de uso da linguagem em processos de versão entre as línguas em diferentes esferas de atuação.

\section{Metodologia}

Tendo como base o materialismo histórico dialético, compreender um fenômeno é compreender as relações sociais e históricas que o engendram. Delimitamos um fenômeno singular, a prática como componente curricular em curso de formação de TILS, podendo contribuir com a compreensão da universalidade, sem negar sua singularidade. Quando nos detemos a estudar a linguagem, discursos e relações de ensino-aprendizagem, precisamos considerar que esses aspectos estão eminentemente envolvidos de ideologia.

Desta forma, trabalhamos com uma abordagem qualitativa de pesquisa, refletindo sobre as contradições da "prática como componente curricular" em aplicação em um curso de bacharelado Letras Libras, trabalhando essencialmente com a interpretação de dados. Trata-se de uma pesquisa descritiva utilizando procedimentos de análise (TRIVIÑOS, 1987). Os documentos analisados foram: 1) o Projeto Político Pedagógico (PPP) do curso de formação de tradutores da UFSC, especialmente no que diz respeito às atividades de PCC; e b) os planos de ensino das disciplinas que têm PCC. Colhemos dados referentes à caracterização geral do curso, ao período da PCC, à carga horária e à atividade que se refere ao PCC em cada disciplina.

Esta investigação tem por objetivo descrever e analisar a configuração curricular da PCC em um curso de Bacharelado em Letras Libras (para formação de tradutores/intérpretes 
de Libras português). Fomos conduzidos por quatro questões de pesquisa: 1) Em que disciplinas as PCCs estão alocadas no currículo? 2) Como o curso o curso de Bacharelado em Letras Libras da Universidade Federal de Santa Catarina tem desenvolvido a Prática de Componente Curricular? 3) Quais atividades são propostas como Prática de Componente Curricular? 4) Quais as implicações destas atividades para formação teórico-prática do futuro profissional?

Acreditamos que esta etapa de caracterização e análise de configurações curriculares é fundamental para futuros estudos que objetivem analisar as implicações didático-pedagógicas da PCC para os cursos de formação e para o processo de construção da identidade do futuro TILS.

\section{Análise dos dados}

A partir da análise dos documentos selecionados, compreendendo seu tempo histórico e social, desenvolvemos a problematização da inserção de atividades práticas ao currículo. Organizamos a construção dos dados sobre a questão levantada em duas categorias de análise: a) Desenho curricular com PCC e b) Saberes pedagógicos dos professores de TILS.

\section{a) Desenho curricular com PCC}

O curso de bacharelado em Letras Libras, conforme seu PPP, tem 3.708 horas-aula, sendo que, destas, 324 horas são destinadas à prática como componente curricular (UFSC, 2012) (quadro 1).

Quadro 1 - Distribuição da Carga Horária

BACHARELADO:

\begin{tabular}{|c|c|c|c|c|}
\hline $\begin{array}{c}\text { Conteúdos } \\
\text { curriculares de } \\
\text { natureza } \\
\text { científico-cultural } \\
\text { (conhecimentos } \\
\text { básicos, } \\
\text { especificos e } \\
\text { profissional) }\end{array}$ & $\begin{array}{c}\text { Estágio } \\
\text { Curricular } \\
\text { Supervisionado }\end{array}$ & $\begin{array}{c}\text { Atividades acadêmico- } \\
\text { científico-culturais }\end{array}$ & $\begin{array}{c}\text { Prática como } \\
\text { componente } \\
\text { curricular }\end{array}$ & Optativas \\
\hline $2.628 \mathrm{~h} / \mathrm{a}$ & $216 \mathrm{~h} / \mathrm{a}$ & $252 \mathrm{~h} / \mathrm{a}$ & $324 \mathrm{~h} / \mathrm{a}$ & $288 \mathrm{~h} / \mathrm{a}$ \\
\hline \multicolumn{7}{|c}{ TOTAL 3.708 h/a } \\
\hline
\end{tabular}

Fonte: UFSC, 2012

O currículo é composto por disciplinas que são de natureza científico-cultural, contemplando eixos do campo da linguística, dos Estudos da Tradução, dos estudos da interpretação, do português e da Libras - as línguas envolvidas no trabalho do tradutor e intérprete, da história e das filosofias da educação de surdos, como apresentado no quadro 2. 
Quadro 2 - Distribuição da Carga Horária

\begin{tabular}{|c|c|c|}
\hline \begin{tabular}{l|l} 
2.3.2 Bacharelado: & DISCIPLINA \\
COD. &
\end{tabular} & $\begin{array}{l}\text { TEÓRICA } \\
\text { Carga horária }\end{array}$ & $\begin{array}{l}\text { PCC* } \\
\text { Carga horária }\end{array}$ \\
\hline \multicolumn{3}{|l|}{ EIXO DE FORMAÇÃO BÁSICA } \\
\hline Introdução aos Estudos Linguísticos & $72 \mathrm{~h} / \mathrm{a}$ & $36 \mathrm{~h} / \mathrm{a}$ \\
\hline Estudos Linguísticos I & $72 \mathrm{~h} / \mathrm{a}$ & \\
\hline Estudos Linguísticos II & $72 \mathrm{~h} / \mathrm{a}$ & \\
\hline Estudos Linguísticos III & $72 \mathrm{~h} / \mathrm{a}$ & \\
\hline Estudos Linguísticos IV & $72 \mathrm{~h} / \mathrm{a}$ & \\
\hline Corporalidade e Escrita & $72 \mathrm{~h} / \mathrm{a}$ & \\
\hline Fundamentos da Tradução e da Interpretação & $72 \mathrm{~h} / \mathrm{a}$ & \\
\hline Metodologia Científica & $72 \mathrm{~h} / \mathrm{a}$ & \\
\hline Total do eixo & $576 \mathrm{~h} / \mathrm{a}$ & \\
\hline \multicolumn{3}{|l|}{ EIXO DE FORMAÇÃO ESPECÍFICA } \\
\hline Fundamentos da Educação de Surdos & $72 \mathrm{~h} / \mathrm{a}$ & \\
\hline Tecnologia da Informação e EaD & $72 \mathrm{~h} / \mathrm{a}$ & \\
\hline Estudos da Tradução I & $72 \mathrm{~h} / \mathrm{a}$ & \\
\hline Estudos da Tradução II & $72 \mathrm{~h} / \mathrm{a}$ & \\
\hline Estudos da Interpretação I & $72 \mathrm{~h} / \mathrm{a}$ & \\
\hline Estudos da Interpretação II & $72 \mathrm{~h} / \mathrm{a}$ & \\
\hline Português I & $72 \mathrm{~h} / \mathrm{a}$ & \\
\hline Português II & $72 \mathrm{~h} / \mathrm{a}$ & \\
\hline Português III & $72 \mathrm{~h} / \mathrm{a}$ & \\
\hline Conversação Intercultural & $72 \mathrm{~h} / \mathrm{a}$ & \\
\hline Libras Iniciante & $144 \mathrm{~h} / \mathrm{a}$ & $36 \mathrm{~h} / \mathrm{a}$ \\
\hline Libras Pré-Intermediário & $216 \mathrm{~h} / \mathrm{a}$ & $36 \mathrm{~h} / \mathrm{a}$ \\
\hline Libras Intermediário & $144 \mathrm{~h} / \mathrm{a}$ & $36 \mathrm{~h} / \mathrm{a}$ \\
\hline Libras Avançado & $144 \mathrm{~h} / \mathrm{a}$ & $36 \mathrm{~h} / \mathrm{a}$ \\
\hline Libras Acadêmica & $72 \mathrm{~h} / \mathrm{a}$ & $36 \mathrm{~h} / \mathrm{a}$ \\
\hline Escrita de Sinais I & $72 \mathrm{~h} / \mathrm{a}$ & \\
\hline Escrita de Sinais II & $72 \mathrm{~h} / \mathrm{a}$ & \\
\hline Estudos Surdos I & $72 \mathrm{~h} / \mathrm{a}$ & \\
\hline Literatura Surda I & $72 \mathrm{~h} / \mathrm{a}$ & \\
\hline Literatura Surda II & $72 \mathrm{~h} / \mathrm{a}$ & $36 \mathrm{~h} / \mathrm{a}$ \\
\hline Total do eixo & $0 \mathrm{~h} / \mathrm{a}$ & \\
\hline \multicolumn{3}{|l|}{ EIXO DE FORMAÇÃO PROFISSIONAL } \\
\hline Laboratório em Interpretação I & $72 \mathrm{~h} / \mathrm{a}$ & $36 \mathrm{~h} / \mathrm{a}$ \\
\hline Laboratório em Interpretação II & $72 \mathrm{~h} / \mathrm{a}$ & $36 \mathrm{~h} / \mathrm{a}$ \\
\hline Laboratório em Interpretação III & $144 \mathrm{~h} / \mathrm{a}$ & \\
\hline Prática de Tradução I & $72 \mathrm{~h} / \mathrm{a}$ & \\
\hline Prática de Tradução II & $144 \mathrm{~h} / \mathrm{a}$ & \\
\hline Estágio em Tradução & $72 \mathrm{~h} / \mathrm{a}$ & \\
\hline Estágio em Interpretação & $144 \mathrm{~h} / \mathrm{a}$ & \\
\hline Trabalho de Conclusão de Curso (TCC) & $72 \mathrm{~h} / \mathrm{a}$ & \\
\hline Total do eixo & $792 \mathrm{~h} / \mathrm{a}$ & \\
\hline TOTAL DOS EIXOS & $3.168 \mathrm{~h} / \mathrm{a}$ & \\
\hline \multicolumn{3}{|l|}{ EIXO DE FORMAÇÃO OPTATIVA } \\
\hline Produção Textual Acadêmica & $72 \mathrm{~h} / \mathrm{a}$ & \\
\hline Sinais Internacionais & $72 \mathrm{~h} / \mathrm{a}$ & \\
\hline Prática de Tradução: Textos Especializados & $72 \mathrm{~h} / \mathrm{a}$ & \\
\hline $\begin{array}{l}\text { História dos Estudos da Tradução e } \\
\text { Interpretação }\end{array}$ & $72 \mathrm{~h} / \mathrm{a}$ & \\
\hline Total do eixo & $288 \mathrm{~h} / \mathrm{a}$ & \\
\hline Atividades acadêmico-científico-culturais & $252 \mathrm{~h} / \mathrm{a}$ & \\
\hline Total das PCC & $324 \mathrm{~h} / \mathrm{a}$ & \\
\hline TOTAL GERAL & $3.708 \mathrm{~h} / \mathrm{a}$ & \\
\hline
\end{tabular}

Fonte: UFSC (2012, pp.29-30)

ALBRES, SOUZA JUNIOR. A prática como componente curricular e sua implementação em um curso de formação superior de tradutores e intérpretes de língua de sinais

Belas Infiéis, v. 8, n. 1, p. 163-188, 2019. DOI: 10.26512/belasinfieis.v8.n1.2019.22632 
Dentre as disciplinas do campo da linguística, a disciplina Introdução aos Estudos Linguísticos foi contemplada com a PCC. Todas as disciplinas de Libras (iniciante, préintermediário, intermediário, avançado e acadêmica) que têm como objetivo o processo de ensino-aprendizagem de Libras preveem a PCC. A orientação é que a PCC seja alocada desde o início do curso, conforme seu projeto pedagógico. As atividades de tradução podem ser desenvolvidas desde o início do curso, distribuídas nas disciplinas de Libras em todos os níveis. Não temos como mencionar a dinâmica prática das disciplinas cuja PCC não consta no projeto, mas apenas aquela de laboratórios e práticas de tradução que estão explicitamente focados na prática, conforme as ementas.

No tocante às disciplinas de Libras, podemos considerá-las essencialmente práticas, considerando que o ensino de língua oferecido aos discentes se faz a partir do uso da língua e que, historicamente, também adota a tradução como atividade pedagógica, ou mesmo como método de ensino de língua em si.

A disciplina de Literatura Surda II também tem PCC, a qual apresenta em seu conteúdo ementário a previsão do trabalho específico com o gênero poético, metáforas e outros recursos

174 literários, o que requer o desenvolvimento de habilidades de tradução para este gênero, que não é contemplado em nenhuma outra disciplina.

No eixo da tradução e interpretação, têm-se as disciplinas: Estudos da tradução I e II e Estudos da Interpretação I e II, com foco essencialmente teórico. Já com foco prático, têm-se três laboratórios de interpretação: Laboratório de Interpretação I - contexto educacional, Laboratório de Interpretação II - contexto de saúde e Laboratório de Interpretação III - contexto jurídico, bem como duas disciplinas de prática de tradução.

Dentre as disciplinas do eixo da tradução e interpretação, que tem como foco a prática de atuação, duas foram contempladas com carga horária de PCC no currículo. São elas: Laboratório de Interpretação I e II. Todavia, as disciplinas de cunho teórico que requereriam uma articulação teoria e prática não foram contempladas com carga horária de atividades de PCC, nem tampouco as ementas indicam conteúdos de cunho prático, ficando a cargo do professor desenvolver a transposição didática.

Considerando a normativa do Conselho Nacional de Educação, apresentada anteriormente, a distribuição da carga horária total da PCC (400h) poderia se dar de maneira equânime entre determinados eixos ou conjuntos de disciplinas teóricas, o que não se observa no documento analisado. 
Desta forma, no desenho curricular, a PCC foi inserida em cinco disciplinas de Libras: uma disciplina da área linguística, uma de literatura surda, e duas disciplinas do campo específico de formação de intérpretes. Conforme indicado no quadro 2, no Projeto do Curso há previsão de que a PCC seja uma atividade extraclasse com carga horária específica, geralmente 36 horas. Todas as outras disciplinas podem ter atividades práticas inseridas nas aulas presenciais, a depender do planejamento dos professores.

Apresentamos a seguir as ementas das disciplinas contempladas com PCC para ilustrar o conteúdo pertinente a cada uma delas:

Quadro 3 - Ementa das disciplinas com prática como componente curricular - PCC

\begin{tabular}{|c|c|}
\hline $\begin{array}{l}\text { FASE DO } \\
\text { CURRÍCULO }\end{array}$ & DISCIPLINA/EMENTA \\
\hline $1^{a}$ fase & $\begin{array}{l}\text { Libras Iniciante (PCC } 36 \text { horas-aula) } \\
\text { Descrição básica de pessoas e cenários. Narrativas pessoais simples. Introdução aos } \\
\text { recursos gramaticais da Libras: uso do corpo e do espaço. Classificadores básicos. Iniciação } \\
\text { à soletração manual e aos numerais. Construções negativas e interrogativas básicas. Prática } \\
\text { como componente curricular. }\end{array}$ \\
\hline $2^{a}$ fase & $\begin{array}{l}\text { Libras Pré-Intermediário (PCC } 36 \text { horas-aula) } \\
\text { Descrições elaboradas de pessoas e cenários. Narrativas pessoais elaboradas. Uso do corpo } \\
\text { e do espaço para estabelecimento de referentes. Diferentes tipos de classificadores. } \\
\text { Coarticulação na soletração manual e de números. Expressão de relações causais simples. } \\
\text { Construções negativas e interrogativas elaboradas. Prática como componente curricular. }\end{array}$ \\
\hline $3^{a}$ fase & $\begin{array}{l}\text { Libras Intermediário (PCC } 36 \text { horas-aula) } \\
\text { Descrições complexas de pessoas, cenários e eventos. Recontagem de narrativas com } \\
\text { enredos complexos. Diferenças de perspectivas na sinalização e o particionamento do corpo } \\
\text { do sinalizante. Expressão de relações causais complexas. Uso avançado de classificadores. } \\
\text { Exploração avançada do corpo e do espaço. Desenvolvimento de fluência na soletração } \\
\text { manual e de números. Introdução ao uso de bóias no discurso. Prática como componente } \\
\text { curricular. }\end{array}$ \\
\hline $3^{a}$ fase & $\begin{array}{l}\text { Introdução aos Estudos Linguísticos (PCC } 36 \text { horas-aula) } \\
\text { Introdução às ciências e à filosofia da linguagem. Definição do campo, do objeto, dos } \\
\text { objetivos e dos métodos da Linguística. Os conceitos de linguagem, língua e fala. O signo } \\
\text { linguístico. As funções da linguagem. Língua e cultura. Descrição/explicação vs. } \\
\text { prescrição. Os níveis da descrição linguística. Noções elementares de história da } \\
\text { Linguística e as abordagens modemas. Mitos sobre LSs. Prática como componente } \\
\text { curricular. }\end{array}$ \\
\hline $4^{a}$ fase & $\begin{array}{l}\text { Libras Avançado (PCC } 36 \text { horas-aula) } \\
\text { Descrições complexas de contextos concretos e abstratos. Definição conceitual de termos. } \\
\text { Argumentação: gerenciamento de razão e emoção. Soletração manual fluente. Narrativas } \\
\text { como forma de argumentação. Exploração coesa e coerente do corpo e do espaço em textos } \\
\text { argumentativos. Exploração avançada das bóias no discurso. Exploração criativa de } \\
\text { classificadores. Estratégias argumentativas. Prática como componente curricular. }\end{array}$ \\
\hline $5^{a}$ fase & $\begin{array}{l}\text { Libras Acadêmica (PCC } 36 \text { horas-aula) } \\
\text { Normatização de trabalhos acadêmicos em Libras. Estrutura do discurso acadêmico } \\
\text { filmado. Tecnologias de vídeo e seu impacto nas pesquisas sobre língua de sinais. } \\
\text { Produções acadêmicas em Libras. Prática como componente curricular. }\end{array}$ \\
\hline $6^{a}$ fase & $\begin{array}{l}\text { Laboratório em Interpretação I (PCC } 36 \text { horas-aula) } \\
\text { Aplicação teórica e prática de interpretação Português - Libras - Português em contextos } \\
\text { educacionais. Prática como componente curricular. }\end{array}$ \\
\hline $7^{a}$ fase & $\begin{array}{l}\text { Laboratório em Interpretação II (PCC } 36 \text { horas-aula) } \\
\text { Aplicação teórica e prática de interpretação Português - Libras - Português em contextos } \\
\text { da saúde. Prática como componente curricular. }\end{array}$ \\
\hline $8^{a}$ fase & $\begin{array}{l}\text { Literatura Surda II (PCC } 36 \text { horas-aula) } \\
\text { Literatura surda no Brasil e no mundo. O gênero poético. Funções da poesia. Tipos de } \\
\text { poesia em línguas de sinais. Poesia e criatividade linguística. Prática em poesia. A } \\
\text { expressividade no humor. Metáforas e outros recursos literários em línguas de sinais. } \\
\text { Prática como componente curricular. }\end{array}$ \\
\hline
\end{tabular}


O projeto pedagógico do curso justifica a inserção da PCC, preconizando a inter-relação teoria e prática, ainda que a exigência legal para tal se aplique apenas aos cursos de licenciaturas, conforme excertos do documento abaixo:

\begin{abstract}
No Projeto Pedagógico dos Cursos de Letras Libras, a prática está inserida no âmbito das mais diversas disciplinas, com carga horária e atividades explicitadas nas respectivas ementas e programas. Transcendendo a sala de aula e permeando toda a formação do licenciado (e, em alguns casos, do bacharel), a inter-relação entre teoria e prática preconizada permitirá tanto a aplicação e/ou transformação do componente teórico em prática pedagógica, como a construção do conhecimento alicerçada na reflexão sobre a realidade, principalmente a realidade educacional (UFSC, 2012, p. 57).

Caracterizam-se como Prática como Componente Curricular (PCC), atividades que estimulem a consciência reflexiva individual e altruísta, visando a autonomia intelectual e profissional do futuro professor, com o objetivo de oportunizar a articulação entre a teoria e a prática desde o início dos cursos. Como o Curso de Letras Libras oferece disciplinas comuns ao Bacharelado e à Licenciatura, mesmo reconhecendo ser o PCC obrigatório somente às licenciaturas, o professor responsável por cada disciplina que envolver horas de PCC deverá diferenciar, em sua prática pedagógica, as atividades a serem desenvolvidas pelos alunos dando oportunidade também ao estudante de Bacharelado de desenvolver atividades práticas que o auxiliem e flexibilizem sua formação (UFSC, 2012, p. 57).
\end{abstract}

Este discurso revela que o que rege o currículo do curso de formação de tradutores e intérpretes é a normativa para a formação de professores, ou seja, a organização curricular do curso de bacharelado está subordinada às necessidades dos cursos de licenciaturas:

A inserção de PCC no Bacharelado pressupõe, ainda, que o profissional de Letras estrangeiras, que não professor, seja beneficiado pela articulação entre teoria e prática, que contribui para a sua formação ampliando horizontes estabelecendo rotinas de questionamento, investigação, análise e aplicação (UFSC, 2012, p. 57).

É necessária a construção de um currículo específico em que seja desenhado um aprofundamento prático para área especializada, uma vez que o modelo para o curso de bacharelado prevê a PCC apenas nas áreas de interpretação educacional e interpretação na saúde. Constatamos que a maior carga horária de PCC se concentra nas disciplinas de Libras, em que os alunos estão aprendendo a língua em um espaço educativo naturalmente marcado pela prática comunicativa.

O projeto encontrou ressonância no cumprimento da legislação para os cursos de licenciatura com a sistematização da PCC no decorrer do curso. Considerando que as disciplinas de Libras são de núcleo comum, ou seja, alunos do curso de licenciatura e bacharelado participam de aulas no mesmo tempo/espaço, potencializando a troca entre surdos e ouvintes, 
e que a maioria dos alunos da licenciatura são surdos, os professores são desafiados a pensar atividades de PCC distintas para a formação teórico-prática profissional dos professores e dos tradutores e intérpretes de Libras.

Quando da organização curricular dos dois cursos, o núcleo de desenvolvimento estruturante (NED), composto por professores, precisa dimensionar a questão da carga horária. Pensando que as disciplinas de Libras são obrigatórias nos dois cursos, há maior concentração de PCC nestas disciplinas.

Neste contexto de necessidades de duplo planejamento, buscamos nos planos de ensino dos professores a transposição didática que desenvolveram nas disciplinas que ministram.

\section{b) Saberes pedagógicos dos professores de TILS}

Dedicamos este tópico à reflexão sobre a produção de saberes didáticos de professores que ministram a PCC em suas disciplinas, registrados em seus planos de ensino. Selecionamos algumas disciplinas de cada eixo como amostra - tendo como meta discutir uma disciplina de cada eixo, considerando o espaço que temos neste artigo.

O professor, especialista em sua disciplina e em uma profissão, constrói historicamente experiências em sala de aula e cria atividades pedagógicas para conduzir os alunos em um campo de conhecimento. Seria possível proporcionar experiências práticas desde o início do curso? Mediante este desenho curricular, que atividades os professores propõem como PCC?

Averiguamos que a PCC está posta desde a primeira fase nas disciplinas de Libras. A disciplina de Libras pré-intermediário foi ministrada por dois professores em turmas diferentes. As atividades propostas foram as seguintes:

Atividade de PCC - Os alunos farão a tradução de histórias em quadrinhos (HQ). Cada grupo escolhe uma história e estuda como traduziriam. Teremos uma aula para trabalhar na tradução que deve ser filmada. $O$ grupo deve ser composto por ouvintes e surdos. Os ouvintes (do bacharelado) devem treinar e os alunos surdos (licenciatura) devem atuar como orientadores e revisores da tradução. Entregar a tradução final editada. (Plano de ensino - Disciplina Libras pré-intermediário, professor 1). 
Atividade de PCC - Os alunos do bacharelado traduzirão uma história infantil. Entregar um relatório do processo de produção da tradução e o vídeo com edição final da tradução. Dividiremos as seguintes histórias: 1 - Chapeuzinho Vermelho, 2 - Três porquinhos, 3 - A Princesa e o sapo, 4 - O Patinho Feio, 5 A dama e o vagabundo, 6 - A bela Adormecida, 7 - Lebre e Tartaruga, 8 Cinderela, 9 - A Branca de Neve, 10 - João e o pé de feijão, 11 - A Formiga e A Cigarra, 12 - Rapunzel, 13 - João e Maria. Os alunos da licenciatura desenvolverão um plano de aula. Dividiremos aos seguintes temas: 1 Classificadores, 2 - Grau comparativo, 3 - Adjetivos [...]. Entregar vídeo em Libras (Plano de ensino - Disciplina Libras pré-intermediário, professor 2).

Como são iniciantes em Libras, os alunos têm níveis bem diversos e dificuldades para trabalhar com tradução de maneira autônoma. O professor 1, considerando que os alunos precisam ser orientados, fez uso de uma aula inteira para que eles gravassem e editassem o vídeo traduzido, ficando nesta aula à disposição para tirar dúvidas quanto à tradução da história e orientá-los como melhor explorar os classificadores (conteúdo da disciplina). Os alunos surdos foram distribuídos entre os grupos para auxiliar os ouvintes em sua produção linguística.

O professor encontrou uma forma de os alunos experienciarem, desde a primeira fase do curso, a tradução. Eles construiriam enunciados em Libras com base em um material textual em português, categorizado como gênero narrativo, explorando aspectos linguístico-discursivos pertinentes a sua disciplina. Como a disciplina é composta por alunos do bacharelado e licenciatura, e a licenciatura tem em sua maioria alunos surdos, considerou ser um exercício interessante colocá-los como orientadores da enunciação em Libras, atividade pertinente para um futuro professor de Libras.

Quando objetiva a formação de aprendizes de língua, a atuação pedagógica deve

[...] focalizar as formas linguísticas que caracterizam cada enunciação, considerandose os recursos disponíveis para concretizá-las, isto é, para cada gênero textual, evidenciar os aspectos da organização gramatical e de suas partes constitutivas que são essenciais para o entendimento de como esses recursos colaboram para a conformação do texto em suas características globais e de sua organização e funcionamento (MILLER, 2009, p. 479 e 480).

Assim, o professor 1 conduziu a atividade de PCC, orientando e colocando os futuros professores surdos para orientar os alunos ouvintes, que em sua maioria são alunos do curso de bacharelado.

Já o professor 2 também solicitou uma atividade de tradução, mas sem orientação e acompanhamento em sala de aula, sendo a atividade executada em casa, individualmente, e 
requerendo uma análise do processo. Ele diferenciou a atividade dos alunos de bacharelado e licenciatura. Constatamos que a complexidade da atividade proposta pelo professor 2 é superior à do professor 1 .

A questão é que, no currículo, a carga horária de PCC corresponde a 36 horas de atividade, e não a 4 horas como executado (conforme dados do professor 1). Cabe perguntar se a carga horária planejada para a atividade é real ou ficcional. A tradução de uma HQ em grupo, iniciada em sala de aula, requer menos tempo que a tradução de uma história infantil produzida individualmente e em casa.

Em termos mais gerais, o ensino de tradução adequado para alunos iniciantes em uma disciplina de Ensino de Libras requer um trabalho mais orientado, discutindo o processo, chamando a atenção para a forma, os modos de enunciar na língua, e relacionando a prática com o conteúdo teórico da disciplina. A esse respeito versa Monteiro (2014):

\begin{abstract}
A função do professor é trabalhar textos, apontar caminhos, fazer sugestões. [...] Opina, dá sugestões, aponta erros e inconsistências. O que diferencia o professor do crítico é que aquele acompanha a elaboração da tradução e, diferentemente deste, ajuda a resolver os problemas que a tradução possa apresentar (MONTEIRO, 2014, p. 144).
\end{abstract}

Esse tipo de atividade não vai ter o mesmo resultado quando proposto para alunos em níveis mais avançados ou executado por profissionais experientes. É relevante pensar que a unidade de tradução apresentada pelos professores é a história como um todo, o que envolve conhecimento linguístico, expressivo e discursivo, e exige, portanto, uma análise detalhada que abrange a leitura e interpretação dos significados postos no texto verbo-visual ${ }^{2}$ de HQ ou no texto da história infantil.

Complementarmente, a inclusão de texto para tradução que compõem um livro infantil com ilustrações favorece o letramento multimodal, como afirma Albres (2015):

[...] cursos de formação de tradutores e intérpretes precisam trabalhar o letramento multimodal, buscando adequar-se às novas materializações dos textos contemporâneos, incorporando textos dos mais variados gêneros híbridos em suas atividades pedagógicas (literatura infanto-juvenil, texto publicitário, histórias em quadrinhos, charges, vídeos multimídia, entre outros), nos quais notamos com mais facilidade a relação intersemiótica (ALBRES, 2015, p.415).

O professor do campo da linguística procurou desenvolver atividade prática investigativa, como visto no enunciado: 
Atividade de PCC - Cada grupo deverá fazer uma pesquisa apresentando, dentre outros, os seguintes tópicos: O que é e qual é o objeto de estudo da área? Histórico da área e principais pesquisadores? Verificar se há trabalhos sobre as línguas de sinais e apresentar exemplos? Qual a contribuição que a área pode trazer para a sua área de formação (professor de Libras, tradutor/intérprete)? Grupos de 3 ou 4 alunos. Cada grupo deverá apresentar um tema diferente e terá o tempo de 20-25 minutos para a apresentação. Todos os alunos devem participar da apresentação. Temas: Psicolinguística, Neurolinguística, Sociolinguística, Linguística Aplicada, Estilística, Política Linguística, Análise do Discurso, Análise da Conversação, Linguística Histórica, Linguística Textual, Antropologia da Linguagem e Filosofia da Linguagem. O objetivo dos trabalhos é apresentar as interfaces da linguística com outras áreas do conhecimento. (Plano de ensino - Disciplina Introdução aos Estudos Linguisticos, professor 3).

Apenas essa disciplina no campo da linguística, que possui caráter introdutório, contou com atividade de PCC, sendo esta uma oportunidade de relacionar teoria e prática já no início do curso. Apesar de Introdução aos Estudos Linguísticos propor uma relação objetiva dos temas propostos com a área de formação, na atividade de PCC consideramos que essa prática não estava relacionada à prática de tradução ou interpretação, e sim à prática investigativa - teórica.

180 Esta prática favorece a reflexão sobre a língua e o caráter interdisciplinar do conhecimento, mas requer do aluno uma autonomia e perspicácia investigativa para relacionar teoria e prática complexas para níveis iniciantes, principalmente em razão de os temas serem de sub-áreas específicas da linguística, o que levaria o aluno a elaborar uma relação entre linguística e Libras, mas não necessariamente refletir sobre os processos de tradução/interpretação dessa língua. Desta forma, o princípio da vivência profissional não foi plenamente contemplado com esta atividade de PCC.

Apresentamos a seguir a PCC das disciplinas do eixo de formação profissional específico.

\footnotetext{
Atividade de PCC - O PCC consistirá na interpretação de diferentes gêneros textuais sorteados em aula. Deverá ser criado um projeto de interpretação com todas as devidas etapas e realizada a interpretação na seguinte forma (Português para Libras). Deve-se produzir um glossário com 5 termos escolhidos pelo aluno a partir da extração terminológicas e incluir como parte do trabalho de PCC. A seguir, o aluno deverá fazer os comentários de análise da interpretação devidamente justificada as decisões tomadas. Após a interpretação deverá ser testada junto a um professor surdo (sorteado anteriormente em aula), o qual deverá emitir análise da produção. Ao final, de posse dos comentários realizados inicialmente pelo aluno e após pelo professor, emitir uma reflexão crítica sobre o processo de interpretação. (Plano de ensino - Disciplina Laboratório de Interpretação I, professor 4).
} 
Segundo o Projeto Político Pedagógico do curso, um conjunto de disciplinas presentes nas etapas finais são puramente práticas, sendo uma delas a disciplina Laboratório de Interpretação I, que é voltada exclusivamente às práticas de interpretação educacional. A atividade de PCC, neste sentido, é incluída na disciplina de maneira redundante à sua natureza e escopo. A disciplina de laboratório por si só tem como característica a prática profissional. Dessa forma, a PCC poderia ser alocada em outra disciplina do curso que não tenha essa natureza, sendo melhor aproveitada em disciplinas caracterizadas como teóricas.

A atividade proposta visou a construir a prática de interpretação como processo e colocou em destaque a relação entre o léxico de especialidade no contexto profissional e a possibilidade de melhoria do produto interpretação pela autocrítica e pela crítica de outrem (professores surdos), em conformidade com o PPP (UFSC, 2012, p. 57). Tal atividade conduziu os estudantes ao caráter reflexivo do ato de traduzir ou interpretar (ROSSI, 2014, p. 76), contudo, cabe problematizar que o uso de textos escritos em construções práticas e que possibilitam o estudo prévio, edição e revisão se aproximam da tarefa de tradução, e não necessariamente da interpretação, como propõe a ementa. Além disso, cabe considerarmos também que a atividade utilizou textos fora do escopo central da disciplina, ou seja, textos educacionais ou didáticos. O professor incluiu no cronograma da disciplina duas aulas finais para que os alunos apresentassem suas atividades de PCC que foram realizadas extraclasse.

Na sequência, há a oferta da disciplina Laboratório de Interpretação II também com PCC. Neste estágio do curso, os alunos também são envolvidos em conteúdos que apontam para a compreensão de conceitos de áreas específicas de atuação, como encontrar termos e formas de traduzir documentação específica, construindo um repertório de termos e fraseologia. Considerando que na área de Libras ainda não temos dicionários por área para servir como consulta, a pesquisa e documentação é uma fonte de aperfeiçoamento da competência linguística. Para tanto, o professor 5 propôs a seguinte atividade: 


\begin{abstract}
Atividade de PCC - Criação de glossários para área médica. Cada aluno receberá 10 termos de uso frequente na área médica. Pesquise o conceito de cada termo. Busque em diferentes fontes o Sinal de cada termo e, não havendo, elabore uma proposta de sinalização para o mesmo (não se trata aqui de criação arbitrária de novos sinais). Em seguida, grave um vídeo com Sinal e o conceito em Libras e poste o mesmo no Fórum do PCC no Ambiente Virtual. Todos deveram assistir aos vídeos e propor melhorias mutuamente. Nas últimas semanas da disciplina todos iremos para o estúdio e gravaremos um DVD com o resultado final da atividade que será nomeado "Dicionário Terminológico da Área de Saúde em Libras". Além do registro em DVD, cada aluno deverá postar na ferramenta 'Glossário' do Ambiente Virtual seus termos conforme o "Modelo de Entrada Terminológica" apresentado. A criação de um blog público com o Dicionário ficará facultativa. (Plano de ensino - Disciplina Laboratório de Interpretação II, professor 5).
\end{abstract}

Assim como ocorreu na disciplina Laboratório de Interpretação I, em Laboratório II o professor procurou relacionar a prática de interpretação, em um contexto específico, neste caso a área de saúde, com a relevância da terminologia para o profissional atuante. Essa relação entre a terminologia, a tradução e a interpretação é destacada por Albir (2011, p. 396) ao apresentar

182 seu modelo holístico de competência tradutória, com destaque para a subcompetência instrumental, a qual ela afirma ser um domínio necessário e que compreende o "conhecimento, essencialmente operativo, relacionado com o uso das fontes documentais e das tecnologias da informação e comunicação (TICs) aplicadas a tradução (dicionários de todo tipo, enciclopédias, gramáticas, livros de estilo, textos paralelos, corpus eletrônico, buscadores, etc.)".

A atividade de PCC envolveu a pesquisa e a tradução da língua portuguesa para Libras e o ambiente virtual de ensino e aprendizagem da disciplina na internet foi incluído como forma de acompanhar e integrar a atividade de todos os alunos e possibilitar a elaboração coletiva extraclasse e o refinamento da prática.

A produção de um material de consulta permanente, resultante da atividade de PCC, apresenta-se salutar para os alunos que incluem um produto real em seus portfólios e, de igual modo, para o curso, que passa a contar com um material físico de referência didática. Embora determinado pelo professor como opcional, a criação do blog público para socializar os resultados da atividade prática poderia desdobrar-se como uma forma de popularizar o conhecimento construído, contribuindo com outros intérpretes e professores da área.

Tagnin (2009, p. 1079) pondera que, como a tarefa principal do tradutor é a produção de um texto natural e fluente nas línguas envolvidas na tradução, ele precisa, então, construir um repertório de como as palavras são usadas e como se associam com outras palavras, 
principalmente quando do uso de linguagem técnica. Em processo de formação, a construção de glossários tem sido importante como uma "prática deliberada", o que, juntamente com um feedback adequado por parte do professor, tem contribuído para o desenvolvimento de técnicas de pesquisa e tradução, levando a um conhecimento especializado que os alunos poderão aplicar em qualquer área em que venham a atuar.

Em síntese, o projeto do curso de bacharelado em Letras Libras buscava um ensino mais prático, em que os alunos pudessem vivenciar atos de sua futura profissão, apoiados e articulados pelo repertório de conhecimento delimitado para cada disciplina. Seria uma forma de vivenciar o conhecimento selecionado e estabelecer ligação entre os conhecimentos científicos veiculados na universidade e as diferentes esferas de atuação do tradutor e intérprete. Constatamos que as atividades propostas como PCC atenderam ao pressuposto de teoriaprática, mas nem sempre especificamente na atuação como tradutor ou intérprete.

\section{Conclusão}

A formação de TILS impõe dificuldades no processo de estabelecimento de um desenho curricular que possa orientar a formação básica acadêmica do tradutor e intérprete para a práxis, ou seja, articulando estudos linguísticos, estudos da tradução, estudos da interpretação e a prática de traduzir e interpretar.

No plano do currículo, a aproximação desses campos (teoria e prática) é possível mediante as atividades pedagógicas propostas em sala de aula e orientadas para a práxis. Constatamos que o currículo do curso analisado impõe essa articulação, principalmente em disciplinas que tenham a PCC, distribuídas desde o primeiro semestre em disciplinas de Libras, linguística e laboratórios de interpretação. A PCC é desenvolvida por meio de atividades anexas às atividades de sala de aula, geralmente como um trabalho final da disciplina que requer empenho e horas extraclasse para serem desenvolvidas.

As atividades incluem a prática de traduzir e interpretar textos e a análise da interpretação. Há atividades que não são de tradução propriamente dita, por exemplo: leitura e escrita - síntese de teorias, pesquisas, consulta a dicionários, preparação de fichas terminológicas e criação de glossários, que compõem passos importantes para a tradução. Esses diferentes tipos de atividades são adequadas para diferentes estágios de aprendizagem e contribuem para a formação teórico-prática do futuro profissional, considerando que o 
preparam para alguns dos desafios da profissão. A PCC contribui para romper com a visão aplicacionista de teorias, favorecendo uma visão ativista da prática desde o início do curso.

Compreendemos que as atividades de práticas que compõem o currículo têm implicações positivas na formação teórico-prática do futuro profissional TILS, pois o aproxima da realidade da carreira, dos problemas de tradução, dos conflitos nas relações interpessoais, dando subsídio para uma melhor atuação e atendimento à comunidade que precisa dos serviços de interpretação Libras e Português.

\section{REFERÊNCIAS BIBLIOGRÁFICAS}

ALBRES, Neiva de Aquino. Processos de produção e legitimação de saberes para o currículo de pós em Libras na formação de intérpretes. Para uma especialização? In: Anais do Congresso de Tradutores intérpretes de Língua de sinais. Eixo temático: Formação de intérpretes de língua de sinais - UFSC. 25 a 27 de novembro de 2010.

ALBRES, Neiva de Aquino. A formação de intérpretes de Libras para um serviço da educação especial. O que os currículos de cursos de especialização em Libras têm a revelar? In: VI Congresso Brasileiro Multidisciplinar de Educação Especial e VII Encontro da Associação Brasileira de Pesquisadores em Educação Especial. Londrina: Editora UEL, 1842011.

ALBRES, Neiva de Aquino. Tradução intersemiótica de literatura infanto-juvenil: vivências em sala de aula. Cadernos de Tradução, Florianópolis, v. 35, n. 2, p. 387-426, out. 2015. Disponível em: https://periodicos.ufsc.br/index.php/traducao/article/view/21757968.2015v35nesp2p387 Acesso em: 11 set. 2018.

ALBRES, Neiva de Aquino; NASCIMENTO, Marcus Vinicius Batista. Currículo, ensino e didática em questão: dimensões da formação de tradutores/intérpretes de língua de sinais. Caderno de Letras (UFPEL), v. 2, p. 221-243, 2014.

APPLE, Michael W. A política do conhecimento oficial: faz sentido a ideia de um currículo nacional? In: MOREIRA, Antônio Flavio e SILVA, Tomaz Tadeu (orgs.). Currículo, cultura e sociedade. São Paulo: Cortez, 2002.

ALMEIDA, Elomena Barbosa. Formação do profissional Intérprete de Língua Brasileira de Sinais: focalizando o papel de professores surdos e ouvintes. Dissertação (Mestrado em Educação). Orientador: Cristina Broglia Feitosa de Lacerda. Universidade Metodista de Piracicaba. 2010.

ALMEIDA, Elomena Barboza de; LODI, Ana Claudia Balieiro. Formação de intérpretes de Libras - língua portuguesa: reflexões a partir de uma prática formativa. In: ALBRES, Neiva de Aquino NEVES, Sylvia Lia Grespan (orgs.) Libras em estudo: formação de profissionais. São Paulo: FENEIS, 2014. Série Pesquisas. pp. 109-129. 
BAKHTIN, Mikhail /VOLOCHÍNOV, Vatentin. [1929]. Marxismo e filosofia da

linguagem. Trad. Michel Lahud e Yara Frateschi Vieira. 9a ed. São Paulo: Hucitec, 1999.

BARBOSA, Alessandro Tomaz; CASSIANI, Suzani. Sentidos da prática como componente curricular nos documentos do conselho nacional de educação. Revista da sbenbio, número 7, outubro de 2014, pp. 195-204. Disponível em: http://www.sbenbio.org.br/wordpress/wpcontent/uploads/2014/11/R0919-1.pdf Acesso em: jan 2019.

BORGES, Cecília; TARDIF, Maurice. Apresentação. Educação \& Sociedade. Campinas, Ano XXII, n. 74, p. 11-26, Abril/2001.

BRASIL. Lei no 11.788 de 25 de setembro de 2008. Dispõe sobre o estágio de estudantes [...]. Disponível em: http://www.planalto.gov.br/ccivil_03/_ato2007-2010/2008/lei/111788.htm. Acesso em: jan 2019.

BRASIL. Resolução do CNE/CP 1, DE 18 de fevereiro de 2002. Institui Diretrizes Curriculares Nacionais para a Formação de Professores da Educação Básica, em nível superior, curso de licenciatura, de graduação plena. Disponível em:

http://portal.mec.gov.br/cne/arquivos/pdf/rcp01_02.pdf Acesso em: jan 2019.

BRASIL. Resolução do CNE/CP 1 de 18 de fevereiro DE 2002. Institui Diretrizes Curriculares Nacionais para a Formação de Professores da Educação Básica, em nível superior, curso de licenciatura, de graduação plena. Disponível em:

http://portal.mec.gov.br/cne/arquivos/pdf/rcp01_02.pdf Acesso em: jan 2019.

BRASIL. Política Nacional de Educação Especial na Perspectiva da Educação Inclusiva. Brasília: MEC/SEESP, 2008. Disponível em:

http://portal.mec.gov.br/arquivos/pdf/politicaeducespecial.pdf Acesso em: 12 abr. 2015.

FARIA, Juliana Guimarães; GALAN-MANAS, Anabel. Um Estudo sobre a Formação de Tradutores e Intérpretes de Língua de Sinais. Trab. linguist. apl., Campinas , v. 57, n. 1, p. 265-286, abr. 2018. Disponível em

<http://www.scielo.br/scielo.php?script=sci_arttext\&pid=S0103-

18132018000100265\&lng=pt\&nrm=iso>. Acesso em: 11 set. 2018.

FERREIRA, Daiane. Estudo comparado de currículos de cursos de formação de tradutores e intérpretes de Libras-Português no contexto brasileiro. Dissertação de mestrado em Estudos da Tradução. Universidade Federal de Santa Catarina, Florianópolis, 2015.

LACERDA, Cristina Broglia Feitosa de. Tradutores e intérpretes de Língua Brasileira de Sinais: formação e atuação nos espaços educacionais inclusivos. Cadernos de Educação (UFPel), v. 36, p. 133-153, 2010.

LIBÂNEO, José Carlos. Produção de saberes na escola: suspeitas e apostas. In:

CANDAU, Vera Maria. (org.). Didática, currículos e saberes escolares.

Rio de Janeiro: DP\&A, 2002 pp.11-44. 
MARSCHARK, Marc; PETERSON, Rico; WINSTON, Elizabeth A. Sign Language Interpreting and Interpreter Education: Directions for Research and Practice. Oxford \& New York: Oxford University Press, 2005.

MARTINS, Vanessa Regina de Oliveira; NASCIMENTO, Vinícius. Da formação comunitária à formação universitária (e vice e versa): novo perfil dos tradutores e intérpretes de língua de sinais no contexto brasileiro. Cadernos de Tradução, Florianópolis, v. 35, n. 2, p. 78-112, out. 2015. Disponível em: $<$ https://periodicos.ufsc.br/index.php/traducao/article/view/21757968.2015v35nesp2p78/30709>. Acesso em: 11 set. 2018.

MATTOS, Delton de. A formação do tradutor em nível universitário. Brasília: Horizonte, 1980. Série Universitária Brasília.

MILLER, Stela. Reflexões acerca da proposta bakhtiniana para uma metodologia do estudo da língua e implicações sobre a profissão docente. In: MENDONÇA, S. G. de L.; SILVA, V. P. e MILLER, S. Marx, Gramsci e Vigotski. Araraquara, SP: Junqueira \& Marin; Marília, SP: Cultura Acadêmica, 2009. p. 475-486.

MONTEIRO, Francisca Ocilma Mendes. A prática como Componente Curricular na formação de professores do Curso de Licenciatura em Biologia do IFPI campus Floriano. Dissertação de mestrado. Programa de pós-graduação em educação. Universidade 186 do vale do rio dos sinos - UNISINOS. 2013. Disponível em: http://www.seduc.pi.gov.br/arquivos/325339141.projeto_apos_qualificacao_e_correcao.pdf Acesso em jan. 2019.

MONTEIRO, Júlio C. Neves. Ensino de Tradução: algumas reflexões sobre a prática de tradução no par espanhol-português. In: FERREIRA, Alice Maria de A.; SOUSA, Germana Henrique P.; GOROVITZ, Sabine. A Tradução na Sala de Aula: ensaios de teoria e prática de tradução. Brasília: Editora UnB, 2014.

MORAES, Sandra Regina Pires de. Prática como componente curricular. Roda de conversa. Universidade Estadual de Goiás - UEG. Disponível em: http://www.cdn.ueg.br/arquivos/PRG/conteudoN/3108/MATERIAL__PRATICA_COMO_COMPONENTE_-_PROFA_SANDRA_MORAES.pdf Acesso em jan. 2019.

MOREIRA, Antônio Flávio Barbosa. O campo do currículo no Brasil: os anos noventa. In: CANDAU, Vera Maria (org.). Didática, currículos e saberes escolares. Rio de Janeiro: DP\&A, 2000.

NAPIER, Jemina. International perspectives on sign language interpreter education. Gallaudet University Press, 2009.

NASCIMENTO, M. V. B. ; BEZERRA, T. C. ; ALBRES, N. A. ; SANTIAGO, Vânia de Aquino Albres. Formação de intérpretes educacionais de libras: entre. In: V Congresso Brasileiro de Educação Especial (V CBEE) / VII Encontro Nacional dos Pesquisadores da Educação Especial (VII ENPEE). São Carlos: UFSCar, 2012. v. 5. p. 11745-11760. 
NASCIMENTO, M. V. B. Gêneros do discurso e verbo-visualidade: dimensões da linguagem para a formação de Tradutores/Intérpretes de Libras/Português. In: BRAIT, Beth;

MAGALHÃES, Anderson (Org.). Dialogismo: teoria e(m) prática. São Paulo: Terra Cota, 2014.

QUADROS, Ronice M. Letras Libras: ontem, hoje e amanhã. Florianópolis: Editora UFSC, 2015.

ROSSI, Ana Helena. Traduzir: aspectos metodológicos e didáticos no ensino da tradução. In: FERREIRA, Alice $M$ de A. et al. A tradução na sala de aula: ensaios de teoria e prática de tradução. Brasília: Editora UnB, 2014.

ROY, Cynthia B. Innovative Practices for Teaching Sign Language Interpreters. Washington D.C.: Gallaudet Press, 2002.

ROY, Cynthia B. Advances in Teaching Sign Language Interpreters. Washington D.C.: Gallaudet Press, 2005.

SANTOS, Silvana. A. Intérpretes de língua de sinais: Um estudo sobre as identidades. Dissertação de mestrado em Educação. Universidade Federal de Santa Catarina, Florianópolis, 2006.

SILVA, César Augusto de Assis. Cultura Surda: agentes religiosos e a construção de uma identidade. São Paulo: Terceiro Nome, 2012.

SOUSA, Aline Nunes de. LEMOS, Andréa Michiles. A avaliação no curso de formação de intérpretes da associação de intérpretes/tradutores de libras do Ceará. In: Anais do Congresso de Tradutores intérpretes de Língua de sinais. Eixo temático: Formação de intérpretes de língua de sinais - UFSC. 25 a 27 de novembro de 2010. Disponível em:http://www.congressotils.com.br/anais/anais2010/andrea_michiles_lemos.pdf

SOUZA NETO[A], Samuel de; SILVA, Vandeí Pinto da. Prática como Componente Curricular: questões e reflexões. Rev. Diálogo Educ., Curitiba, v. 14, n. 43, p. 889-909, set./dez. 2014.

TAGNIN, Stella E. O. Produção de glossários direcionados pelo corpus e orientados ao tradutor como metodologia de formação de tradutores. In: Anais do X Encontro Nacional de Tradutores \& IV Encontro Internacional de Tradutores (ABRAPT-UFOP, Ouro Preto, de 7 a 10 de setembro de 2009). Disponível em:

http://comet.fflch.usp.br/sites/comet.fflch.usp.br/files/u30/GLOSSARIOS.pdf Acesso em: jan. 2019.

UFSC. Projeto político pedagógico do curso de letras libras Licenciatura e Bacharelado Modalidade Presencial Currículo 2012.1. Disponível em: <http://letraslibras.grad.ufsc.br/files/2013/04/PPPLibras_Curriculo_2012_FINAL_06-032014.pdf >. Acesso em: jan. 2019. 
TRIVIÑOS, A. N. S. Introdução à pesquisa em ciências sociais: a pesquisa qualitativa em educação. São Paulo: Atlas, 1987.

WASLI. Wasli Interpreter Education Guidelines. Disponível em: <http://wasli.org/wpcontent/uploads/2018/03/WASLI-Training-Guidelines-Aug-2017-1.pdf.> Acesso em: 11 set. 2018.

\footnotetext{
${ }^{i}$ Neiva de Aquino ALBRES - Doutora em Educação Especial (2013) pela Universidade Federal de São Carlos. Mestre em Educação (2005) pela Universidade Federal de Mato Grosso do Sul. Especialista em psicopedagogia (2002) pela Universidade Anhanguera. Licenciada em Normal Superior (2003) pela Universidade Estadual de Mato Grosso do Sul. Graduada em fonoaudiologia (1999) pela Universidade Católica Dom Bosco. Realizou estágio de pós-doutorado na Universidade de São Paulo. Professora titular na Universidade Federal de Santa Catarina. Florianópolis, Santa Catarina, Brasil.

Lattes: http://lattes.cnpq.br/1652645656634694 E-mail: neiva.albres@ufsc.br

ii José Ednilson Gomes de SOUZA JUNIOR - Mestre em linguística (2012) pela Universidade de Brasília. Bacharel em Comunicação Social (2007) pela Faculdade Estácio de Sá. Professor na Universidade Federal de Santa Catarina. Florianópolis, Santa Catarina, Brasil.

Lattes: http://lattes.cnpq.br/0519894675464006 E-mail: jose.souza.junior@ufsc.br

${ }^{1}$ Essas Resoluções foram revogadas em 2015 pela Resolução CNE/CP n. 02/2015. Contudo, são estas as resoluções que nortearam o atual Projeto Político Pedagógico do curso analisados nesta pesquisa. Na normativa atual, permanecem os princípios que norteiam a base comum nacional para a formação inicial e continuada, como a unidade teoria-prática. No entanto, ela amplia a carga horária do PCC, indicando no Capítulo V, Art. 13. "I - 400 188 (quatrocentas) horas de prática como componente curricular, distribuídas ao longo do processo formativo". Veja mais em: http://portal.mec.gov.br/docman/agosto-2017-pdf/70431-res-cne-cp-002-03072015-pdf/file
}

${ }^{2} \mathrm{O}$ termo verbo-visual remete conceitualmente ao linguístico e ao não linguístico, coadunando a enunciação materializada. Poderia causar estranheza empregar este termo para o estudo de línguas de sinais, considerando que elas são de modalidade gestual-visual e de cunho linguístico, pois são línguas. Todavia, pesquisadores de línguas de sinais o têm empregado, compreendendo que a porção verbal se refere à língua de sinais (linguística) e o termo visual refere-se a outras linguagens que co-ocorrem no processo de sinalização, colaborando para a construção de sentidos dos sujeitos em interlocução. Assim, "o verbal também é visual, tal como a língua escrita também é. No entanto, a visualidade da língua de sinais possui sua especificidade por ser, além de visual, gestual” (NASCIMENTO, 2014, p.220). 